This item was submitted to Loughborough's Research Repository by the author.

Items in Figshare are protected by copyright, with all rights reserved, unless otherwise indicated.

\title{
Inter-limb strength asymmetry in adolescent distance runners: Test-retest reliability and relationships with performance and running economy
}

\section{PLEASE CITE THE PUBLISHED VERSION}

https://doi.org/10.1080/02640414.2020.1820183

\section{PUBLISHER}

Informa UK Limited

\section{VERSION}

AM (Accepted Manuscript)

\section{PUBLISHER STATEMENT}

This is an Accepted Manuscript of an article published by Taylor \& Francis in Journal of Sports Sciences on 13 Sep 2020, available online: https://doi.org/10.1080/02640414.2020.1820183

\section{LICENCE}

CC BY-NC-ND 4.0

\section{REPOSITORY RECORD}

Blagrove, Richard, Chris Bishop, Glyn Howatson, and Philip R Hayes. 2020. "Inter-limb Strength Asymmetry in Adolescent Distance Runners: Test-retest Reliability and Relationships with Performance and Running Economy". Loughborough University. https://hdl.handle.net/2134/13232342.v1. 


\title{
Inter-limb strength asymmetry in adolescent distance runners: test-retest reliability and relationships with performance and running economy
}

\author{
Richard C Blagrove ${ }^{1}$, Chris Bishop ${ }^{2}$, Glyn Howatson ${ }^{3,4}$, and Philip R Hayes ${ }^{3}$ \\ ${ }^{1}$ School of Sport, Exercise and Health Sciences, Loughborough University, Loughborough, \\ Leicestershire, United Kingdom. \\ ${ }^{2}$ Faculty of Science and Technology, London Sports Institute, Middlesex University, London, United \\ Kingdom. \\ ${ }^{3}$ Faculty of Health and Life Sciences, Division of Sport, Exercise and Rehabilitation, Northumbria \\ University, Northumberland Building, Newcastle-upon-Tyne, United Kingdom. \\ ${ }^{4}$ Water Research Group, Northwest University, Potchefstroom, South Africa.
}

Dr Richard Blagrove (corresponding author)

Tel.: +441509 226383

Email: R.C.Blagrove@lboro.ac.uk

Twitter:@rich_blagrove

Dr Chris Bishop

Tel.: +4420 47758411

Email: C.Bishop@mdx.ac.uk

Twitter:@ChrisBishop_UK

Professor Glyn Howatson

Tel.: +441912273573

Email: glyn.howatson@nothumbria.ac.uk

Twitter:@GlynHowatson

Dr Philip Hayes

Tel.: +441912274690

Email:phil.hayes@northumbria.ac.uk

Twitter:@phil_hayes_13

\section{Funder information:}

No funding was received for this study.

\section{Declarations of interest:}

The authors report no conflict of interest.

\section{Data availability:}

Data can be made fully available upon request.

Word count: 4738 


\title{
Inter-limb strength asymmetry in adolescent distance runners: test-retest reliability and relationships with performance and running economy
}

\begin{abstract}
The purpose of this investigation was, firstly, to quantify the test-retest reliability of strength measures in adolescent distance runners; and secondly, to explore the relationships between inter-limb strength asymmetry and performance and running economy (RE) in a similar cohort of young runners. For the reliability study, twelve ( $n=6$ female) post-pubertal adolescent distance runners performed an isometric quarter-squat on a dual force plate and unilateral isometric hip extension and hip abduction tests on two occasions. For the correlation study, participants $(n=31)$ performed the strength tests plus a submaximal incremental running assessment and a maximal running test. Running economy was expressed as the average energy cost of running for all speeds below lactate turnpoint and was scaled for body mass using a previously calculated power exponent. Allometrically scaled peak force during the quarter-squat and peak torque in the hip strength tasks showed acceptable levels of reproducibility (typical error $\leq 6.3 \%$ ). Relationships between strength asymmetry and performance and RE were low or negligible $(r<0.47, p>0.05)$, except for hip abduction strength asymmetry and RE in the female participants $(r=0.85, p<0.001, n=16)$. Practitioners should consider inter-limb hip abduction strength asymmetry on an individual level, and attempting to reduce this asymmetry in females may positively impact RE.
\end{abstract}

Keywords: symmetry, imbalance, between-limb difference, endurance running 


\section{Introduction}

Distance running performance is influenced by several important determinants, including maximal oxygen uptake $\left(\dot{V} \mathrm{O}_{2 \max }\right)$ and running economy $(\mathrm{RE})^{1,2}$. Defined as the energy cost of covering a given distance, RE can vary considerably in groups of runners with similar $\dot{V} \mathrm{O}_{2 \max }$ values, and improvements in RE appear to be closely related to positive changes in performance ${ }^{3}$. The factors underpinning the manifestation of RE are complex and the result of interactions between a runner's anthropometrics, physiology and biomechanics ${ }^{4}$. There is also evidence that neuromuscular-related qualities are important for $\mathrm{RE}^{5}$, and improvements in strength can enhance $\mathrm{RE}^{6}$. Although neuromuscular capabilities appear to be important for running performance and RE, differences in force-producing capabilities between limbs within individuals has seldom been considered as a factor that may also influence these outcomes.

Inter-limb asymmetry represents the ratio between the performance of one limb with respect to the other ${ }^{7}$. It is often assumed by coaches and runners that inter-limb asymmetry is associated with injury risk and poor performance, so should be minimised; however, evidence for this conjecture in runners is currently lacking. Running biomechanics are generally reported as being symmetric; however, kinetic asymmetry in healthy young boys has previously been observed ${ }^{8}$. Studies examining the relationship between inter-limb biomechanical asymmetry and the metabolic cost of locomotion have reported mixed results with higher ${ }^{9,10}$ or similar $^{11}$ energy expenditure compared to symmetric runners. Individuals with pathology ${ }^{12}$, amputation ${ }^{13}$ or an injury that causes unilateral physical impairment ${ }^{14}$ also display asymmetric biomechanics and increased energy cost during locomotion compared to more symmetric controls.

Although asymmetry is usually assessed within the biomechanics of a sports-specific skill, bilateral ${ }^{15,16}$ and unilateral ${ }^{15,17}$ strength-based tests have been used to quantify inter-limb asymmetry and its relationship with performance-related outcomes. Greater bilateral force asymmetry has been associated with poorer jumping performance ${ }^{16,18}$, and interestingly, stronger athletes tend to have less strength asymmetry than their weaker counterparts ${ }^{16}$. In endurance cyclists, Rannama and colleagues ${ }^{17}$ observed a modest negative relationship $(r=-0.50)$ between isokinetic $\left(180^{\circ} \cdot \mathrm{s}^{-1}\right)$ knee extensor strength asymmetry and mean relative power $\left(\mathrm{W} \cdot \mathrm{kg}^{-1}\right)$ during a 5-s sprint; however, there are currently no similar investigations in endurance runners.

Rapid bone and muscle growth during the pubertal years often results in muscular imbalances and reduced neuromuscular control ${ }^{19}$, which might influence movement efficiency and performance. However, the majority of research investigating inter-limb asymmetry in runners has used adult participants. Given the importance of RE for performance in adolescent distance runners ${ }^{2}$ and the rapid changes in strength that occur around peak height velocity ${ }^{20}$, it seems prudent to investigate how strength asymmetry might influence this age group. Recent studies have shown relationships exist 
between inter-limb asymmetry from unilateral jump tests and sprint speed in youth games players ${ }^{21,22}$. Furthermore, high levels of inter-limb asymmetry (10-20\%) in horizontal and vertical force ${ }^{23}$, and in leg stiffness ${ }^{8}$, during sprinting have been observed in post-pubertal male adolescents. However, there is currently an absence of research examining how asymmetry could affect performance of more prolonged running in adolescent athletes.

The day-to-day consistency of strength measures and the direction of asymmetry appears to be taskand variable-dependent, with more technically challenging skills displaying larger variability compared to simple tasks ${ }^{24}$. This is likely to be further compounded in participants who are weaker ${ }^{25}$ or unfamiliar with a test protocol, such as adolescents. Peak force during isometric mid-thigh pull and quarter-squat tests is a valid indicator of multi-joint lower limb maximal strength ${ }^{26}$, and has consistently been shown to be the most reliable kinetic variable in athletes ${ }^{24,27-29}$; however, the inter-session consistency of this metric is yet to be established in non-strength-trained adolescent athletes.

Due to their low cost and portability, strain gauge dynamometers are popular in both research- and fieldbased settings as a valid way to measure strength isometrically at various joints ${ }^{30,31}$. The inter-session reliability of data gathered from strain gauges been addressed in several studies ${ }^{31-33}$; however, differences in device, protocols and testing positions make comparisons problematic, and data in adolescent participants is currently lacking. Quantifying the systematic and biological error associated with intra-limb strength measures is therefore important, to enable true inter-limb asymmetry to be determined ${ }^{34}$.

The aims of this study were to 1) quantify test-retest reliability of strength measures in a group of competitive adolescent distance runners, and 2) determine the relationships between inter-limb strength asymmetry and both performance and RE in a cohort of adolescent distance runners. 


\section{Materials and Methods}

\section{Study design}

The study received institutional-level ethical approval and was conducted in accordance with the Helsinki Declaration. This investigation was conducted in two stages, a test-retest reliability component to quantify the variability of measures (part A), and a correlational study to determine the relationships between strength asymmetry, and RE and performance (part B). For the reliability data collection, participants visited the laboratory on three separate occasions separated by at least $48 \mathrm{~h}$, but no longer than one week. All data were collected by the same investigator. The first trial was used to familiarise participants with the bilateral isometric quarter-squat, and unilateral isometric hip extension and hip abduction testing protocols. The second and third trials were used to assess maximal strength during these same tasks.

For the correlation component of the study, participants were required to attend two testing sessions. The first session involved a submaximal discontinuous incremental running test and continuous incremental test to volitional exhaustion, followed $30 \mathrm{~min}$ later by familiarisation to the strength tests. The second laboratory visit involved assessment of strength using identical procedures to those of the familiarisation and reliability data collection.

\section{Participants}

Twelve participants volunteered for part A of the study, and 31 participants were recruited for part B. An a priori sample size estimation $(\mathrm{G} *$ Power 3.1.9.2) revealed that 29 participants were required for part B of the study to achieve statistical power of $80 \%$, at a $5 \%$ probability threshold, and an estimated correlation coefficient of $0.5^{17}$. Participants were recruited by contacting local athletics clubs and coaches. Characteristics of the participants are shown in Table 1. To be eligible to take part, participants were required to meet the following inclusion criteria: age 15-18 years, non-strength-trained, injuryfree in the month preceding the study, competitive middle- $(0.8-3 \mathrm{~km})$ or long-distance $(5-10 \mathrm{~km}$ and cross-country) runners. Prior to commencing the study, signed consent was gained from a parent or legal guardian, and for those age 18 years, consent was provided by the participant.

Table 1. Descriptive characteristics of study participants (data are mean \pm standard deviation).

\begin{tabular}{ccccc}
\hline & \multicolumn{2}{c}{ Reliability participants } & \multicolumn{2}{c}{ Correlation participants } \\
& $\mathrm{M}(n=6)$ & $\mathrm{F}(n=6)$ & $\mathrm{M}(n=15)$ & $\mathrm{F}(n=16)$ \\
\hline Age (years) & $17.4 \pm 1.7$ & $18.1 \pm 0.9$ & $17.1 \pm 1.4$ & $17.3 \pm 1.2$ \\
Body mass (kg) & $64.4 \pm 6.7$ & $55.0 \pm 5.2$ & $62.5 \pm 7.2$ & $52.9 \pm 4.7$ \\
Stature (m) & $1.77 \pm 0.07$ & $1.71 \pm 0.06$ & $1.75 \pm 0.06$ & $1.69 \pm 0.06$ \\
Maturity offset (years) & $3.5 \pm 1.4$ & $4.6 \pm 1.2$ & $3.3 \pm 1.2$ & $4.2 \pm 1.1$ \\
$\mathrm{IAAF}$ performance (points) & $791 \pm 137$ & $838 \pm 52$ & $760 \pm 170$ & $913 \pm 85$ \\
$\dot{V} \mathrm{O}_{2 \max }\left(\mathrm{ml}^{-1} \mathrm{~kg}^{-1} \mathrm{~min}^{-1}\right)$ & - & - & $68.7 \pm 8.9$ & $59.7 \pm 6.2$ \\
\hline
\end{tabular}


$\mathrm{M}$ male; F female; IAAF International Association of Athletic Federations; $\dot{V} \mathrm{O}_{2 \max }$ maximal oxygen uptake

\section{Procedures}

\section{Isometric quarter-squat}

The bilateral isometric quarter-squat was performed in a custom-built adjustable back-squat rig. Participants gripped a fixed bar, positioned across their upper back, with the bar set to a height that enabled participants to adopt a quarter-squat position with the internal knee joint angle at $140^{\circ}$. This approximates the knee angle during the mid-stance phase of sub-maximal running ${ }^{35}$. This position was established during the familiarisation session using a goniometer (Jamar 7514, Patterson Medical, Nottinghamshire, UK), and an identical set-up was used in subsequent trials. Participants stood on dual force plates (PASPORT PS2141, PASCO, Roseville, CA, USA) to enable force to be captured through each leg. Data were sampled at $1000 \mathrm{~Hz}$ and participants were instructed to push against the bar as hard as possible for 3-4 s. Two warm-up repetitions preceded three recorded attempts in which strong verbal encouragement was provided. Attempts were each separated by $90 \mathrm{~s}$ of rest. Peak force was defined as the highest force value produced during the repetition.

\section{Isometric hip extension}

Unilateral isometric hip extension peak torque was measured in a prone position on a portable bench set $0.8 \mathrm{~m}$ off the ground. Participants were positioned with feet and ankles overhanging the bench and strapped securely down across the hips to minimise extraneous movement. Force was recorded using a strain gauge tension dynamometer (MIE Medical Research Ltd., Leeds, UK) anchored to the ground and positioned perpendicular to the participant's tibia via an inextensible webbing strap $(3 \mathrm{~cm}$ width) fastened $5 \mathrm{~cm}$ superior to the lateral malleolus (Figure 1a). Maintaining a straight leg $\left(0^{\circ}\right.$ knee flexion), participants were instructed to push their heel upwards in the opposite direction to the strain gauge attachment.

\section{Isometric hip abduction}

Using an identical equipment set-up to the hip extension test, unilateral isometric hip abduction strength was assessed with the participant lying on their side, strapped down, with hips perpendicular to the bench. Participants flexed the hip and knee of their bottom leg to an angle of $\sim 45^{\circ}$ and $\sim 90^{\circ}$ respectively, maintaining a straight top leg in zero degrees of hip flexion (Figure 1b). With the ankle strap attached in the same anatomical position as the hip extension test, participants were instructed to push their top leg vertically upwards whilst maintaining an extended knee and fixed hip position.

For both hip strength tests, participants were permitted two warm-up repetitions prior to three maximal efforts, interspersed by $60 \mathrm{~s}$ of rest. Verbal encouragement was provided, and participants were 
instructed to grip the bench to facilitate bracing. The protocol was performed on the right leg followed by the left leg.

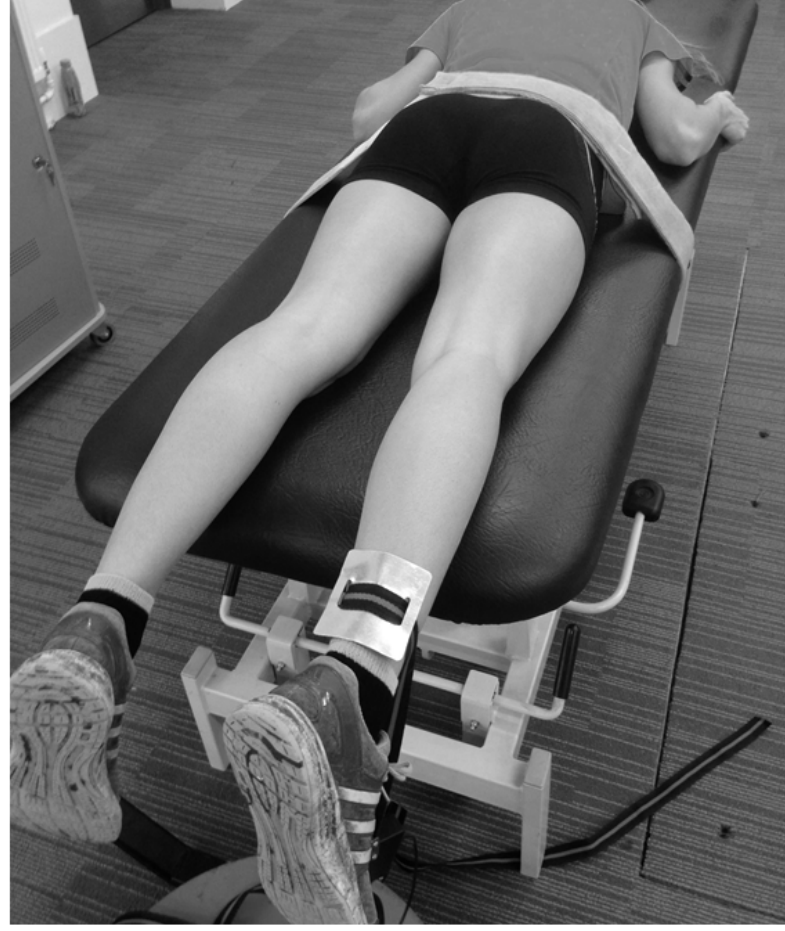

(a)

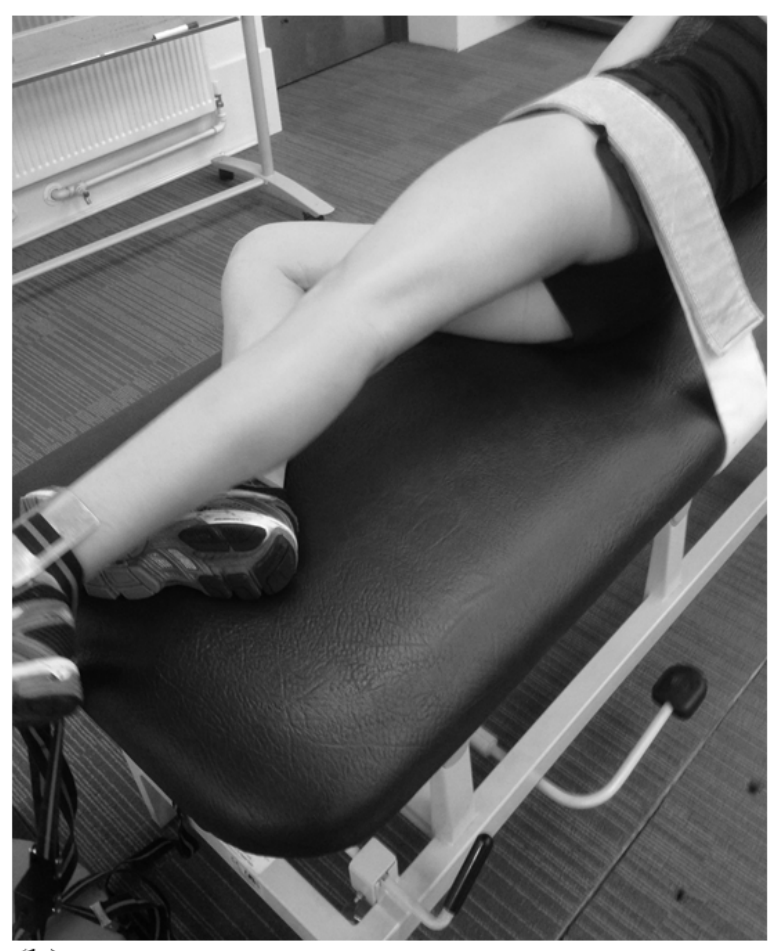

(b)

Figure 1. Unilateral isometric test set-ups: (a) hip extension (b) hip abduction

\section{Sub-maximal running assessment}

The running test took place on a motorized treadmill (HP Cosmos Pulsar 4.0; Cosmos Sports \& Medical $\mathrm{GmbH}$, Munich, Germany) under similar laboratory conditions for all participants (temperature $16^{\circ} \mathrm{C}-$ $20^{\circ} \mathrm{C}$; relative humidity $29 \%-50 \%$; barometric pressure $746-773 \mathrm{mmHg}$ ). Participants were asked to refrain from strenuous exercise in the $48 \mathrm{~h}$ prior to testing and arrive $\geq 2 \mathrm{~h}$ post-prandial. Throughout testing, participants breathed through a low-dead space mask attached to a two-way valve with dual gas sensor. Expired air was monitored continuously via an automated open circuit metabolic cart (Oxycon Pro; Enrich Jaeger GmbH, Hoechberg, Germany), which quantified pulmonary ventilation, oxygen uptake $\left(\dot{V} \mathrm{O}_{2}\right)$, carbon dioxide production $\left(\dot{V} \mathrm{CO}_{2}\right)$, and the respiratory exchange ratio (RER). Prior to every test, both gas analysers were calibrated with known concentrations of standard calibration gas $\left(16 \% \mathrm{O}_{2} ; 5 \% \mathrm{CO}_{2}\right)$, and the ventilation measurement unit with a 3-L syringe. Heart rate (HR) was also monitored continuously via a telemetry chest strap (Polar RS400; Polar Electro Oy, Kempele, Finland).

Following a 5-min warm-up, participants completed a discontinuous incremental running test involving five to seven stages of $3 \mathrm{~min}$, with the treadmill gradient set to $1 \%$. A judgment of the most appropriate 
speed for the first stage of the test was made based upon the participant's best race times, their HR response during warm-up, and published recommendations ${ }^{36}$. The start speed was sufficiently slow to provide at least three speeds below lactate turn point (LTP; rise of $>1 \mathrm{mmol}^{-1}$ relative to previous stage). The treadmill speed was increased by $1 \mathrm{~km} \cdot \mathrm{h}^{-1}$ each stage, interspersed by $30 \mathrm{~s}$ passive rest to allow for extraction of a $20-\mu 1$ sample of capillary blood from the earlobe. Each sample was hemolysed and subsequently analysed for blood lactate concentration (Biosen C-Line, EKF Diagnostic, Barleben, Germany). The analyser was calibrated before all trials with a known concentration of blood lactate and in accordance with the manufacturer's instructions.

\section{Maximal running assessment}

Once LTP had been surpassed, participants passively rested for $5 \mathrm{~min}$ before completing a continuous incremental test to determine $\dot{V} \mathrm{O}_{2 \max }$. The treadmill speed was set to the participants' speed at LTP (sLTP) and gradient initially raised to $1 \%$. At the end of each minute the gradient increased by $1 \%$ until volitional exhaustion was reached, which typically took 6-8 min. A participant's $\dot{V} \mathrm{O}_{2 \max }$ was defined as the highest $\dot{V} \mathrm{O}_{2}$ achieved in a $30 \mathrm{~s}$ period on the maximal test.

\section{Measurements}

\section{Anthropometrics}

Prior to each trial, participants' body mass was measured with digital scales to the nearest $0.1 \mathrm{~kg}$ (MPMS-230; Marsden Weighing Group, Oxfordshire, UK). Stature and sitting height were also recorded to the nearest $1 \mathrm{~cm}$ using a manual stadiometer (SECA GmbH \& Co, Hamburg, Germany). These data were used to calculate estimated years from peak height velocity ('maturity offset') using a validated equation ${ }^{37}$. Prior to strength testing, leg length was also measured as the distance between the greater trochanter and the lateral malleolus.

\section{Strength Asymmetry}

The best score over the three attempts in each strength test was used for analysis and each limb was denoted as the stronger or weaker. Various methods of calculating inter-limb asymmetry have used within the literature, with the relative merits and limitations of various equations discussed elsewhere ${ }^{7}$. Recent literature has suggested that any between-limb difference from bilateral tests should be interpreted relative to the sum total because both limbs interact together to produce a total output ${ }^{38}$. In contrast, no contribution exists from the opposing limb during unilateral tests; thus, the calculation of asymmetry has been suggested to adhere to fundamental mathematical principles when quantifying percentage differences. Therefore, to quantify asymmetry in the bilateral quarter-squat test, the 'symmetry index' equation was applied: 


$$
\text { Symmetry index }(\%)=\frac{(\text { stronger limb }- \text { weaker limb })}{\text { total }} \times 100
$$

For the unilateral hip strength tests, torque was calculated as the product of peak force and the lever arm length (defined as the distance between the greater trochanter and the middle of the strap). Interlimb asymmetry was calculated using the strength asymmetry equation:

$$
\text { Strength asymmetry }(\%)=\frac{(\text { stronger limb }- \text { weaker } \operatorname{limb})}{\text { stronger limb }} \times 100
$$

\section{Performance}

Participants fastest times over $0.8,1.5,3$ and $5 \mathrm{~km}$ during competitive track races, within 60 days of laboratory testing, were converted to points using the International Association of Athletics Federations scoring tables of athletics (www.worldathletics.org/about-iaaf/documents/technical-information). For a time to be considered, at least two race performances over that distance had to be recorded during the competitive outdoor track season. The event that generated the highest points for each participant was used for data analysis.

\section{Running economy}

Oxygen uptake and $\dot{V} \mathrm{CO}_{2}$ data were initially filtered to remove any erroneous values. The presence of a steady-state $\dot{V} \mathrm{O}_{2}$ was confirmed by comparing the difference between the final $30 \mathrm{~s}$ of each stage and the preceding $30 \mathrm{~s}$. A difference of less than the minimal detectable change (MDC) value (calculated as standard error of the mean $\mathrm{x} 1.96 \mathrm{x} \sqrt{2}$ ) confirmed that a $\dot{V} \mathrm{O}_{2}$ plateau had been achieved. Stages where it was deemed steady-state had not been achieved and were removed from subsequent analysis. Running economy was expressed as energy cost, rather than oxygen cost, to account for differences in substrate utilisation, which provides the most valid reflection of metabolic cost of exercise in adolescent runners ${ }^{2}$. Energy cost of running for each stage was estimated from updated non-protein quotient equation $s^{39}$ and the RER values. These values were then added and multiplied by 4.182 to determine energy cost in $\mathrm{kJ}$. As speed at SLTP varied across participants, RE was expressed as the average energy cost of running per km for all speeds below a participant's SLTP. Reliability of RE in a similar cohort of participants has previously been reported ${ }^{40}$.

\section{Allometric scaling}

To account for the confounding influence of body mass between participants, a ratiometric index tends be applied when scaling physiological attributes such as strength and RE. However, this approach lacks validity, as often the correlation coefficient between the normalised values and body mass does not approach zero ${ }^{41}$. In order to assess a participant's physiological capabilities independent of body dimensions, recorded absolute values should be normalised using an appropriate scaling exponent for 
the group of participants under investigation ${ }^{41,42}$. The process used to calculate appropriate scaling factors for isometric quarter-squat strength and RE in this cohort of participants is described elsewhere ${ }^{2,43}$. Briefly, data from larger cohorts of adolescent distance runners (peak force, $n=36$; RE, $n=56$ ) were log-transformed and linear regression lines compared for males and females using an analysis of co-variance model. Homogeneity of regression for the slopes was observed; thus, a common power function was calculated for both data sets via linear regression on the log-transformed data. Exponents of $b=0.61$, and $b=0.75$ were obtained for peak force ${ }^{43}$ and $\mathrm{RE}^{2}$, respectively and were used to scale absolute isometric quarter-squat peak force $\left(\mathrm{N}^{\mathrm{kg}} \mathrm{kg}^{-0.61}\right)$ and energy cost $\left(\mathrm{kJ}^{\mathrm{k}} \mathrm{kg}^{-0.75} \mathrm{~km}^{-1}\right)$ for body mass.

\section{Statistical analysis}

The Shapiro-Wilk statistic revealed that performance data and strength asymmetry variables had nonnormal distributions $(p<0.05)$. All data points fell within \pm 3.29 standard deviations from the mean; therefore, none were considered outliers. Inspection of the scatter plots of the residual errors and predicted values showed that all variables possessed homoscedastic properties.

Test-retest reliability was quantified using typical error (TE), calculated as the standard deviation (SD) of the differences between trials divided by $\sqrt{2}$. Minimum detectable change values at a $95 \%$ confidence interval $\left(\mathrm{MDC}_{95}\right)$ were also generated for each asymmetry variable, calculated as TE x $1.96 \times \sqrt{2}$. Effect sizes were quantified as the change in the mean scores between trials divided by the pooled SD from both trials and interpreted as trivial $<0.20$; small $0.20-0.59$; moderate $0.60-1.19$ and large $\geq 1.20$. Two-way random (single measure) intra-class correlation coefficient (ICC) values were also computed, including a 95\% confidence interval (CI). Finally, Kappa coefficients were calculated as a measure of agreement between tests for the direction of asymmetry and interpreted as slight $\leq 0.20$; fair $0.21-0.40$; moderate $0.41-0.60$; substantial $0.61-0.80$ and almost perfect $>0.80$.

Two-tailed Spearman rank order correlation coefficients were calculated for each strength asymmetry metric for running economy and performance. Data were analysed for males and females separately, and the sexes combined. As three asymmetry metrics were tested against the same performance or RE data, the Bonferroni correction was applied to reduce the risk of a type I error. Correlation coefficients were interpreted as negligible $\leq 0.30$; low $0.31-0.50$; moderate $0.51-0.70$; high $0.71-0.90 ;>0.90$ very high. Participants that recorded an asymmetry value that exceeded the $\mathrm{MDC}_{95}$ were grouped together ('asymmetric') and compared against those participants with asymmetry values under the $\mathrm{MDC}_{95}$ threshold ('non-asymmetric'). Levene's test revealed equality of variances across all betweengroup comparisons for RE; therefore, two-tailed independent samples T-tests were utilised for RE and Mann-Whitney U tests for performance. Differences between the sexes for asymmetry were also 
explored using Mann-Whitney U tests. Effect size (ES) statistics were calculated for between-group analyses by expressing the difference between group means in terms of their combined SD. Except for ICC tests, reliability statistics were computed using Microsoft Excel. All other statistical tests were performed in IBM SPSS Statistics (v24). Data are presented as mean \pm SD, unless stated, and the alpha level set at $p<0.05$.

\section{Results}

Estimation of maturity offset and $\dot{V} \mathrm{O}_{2 \max }$ values are presented as part of Table 1 . All participants were considered post-pubertal ( $\geq 1.0$ year), even when the error associated with the method of calculation was accounted for (Moore et al., 2015). Table 2 shows the test-retest reliability for the strength measures. Unilateral hip extension and abduction peak torque demonstrated high reliability ( $\mathrm{ES} \leq 0.22$, small or trivial; TE $\leq 3 \%$; ICC $\geq 0.97$ ) and 'substantial' agreement in the consistency of asymmetry direction $(\kappa \geq 0.66)$. The reproducibility of peak force during the bilateral isometric quarter-squat was more variable. Although excellent reliability was observed for peak force through the right leg (ES = 0.41 , small; $\mathrm{TE}=3.6 \%$; ICC $=0.86$, the left leg displayed less consistency $(\mathrm{ES}=0.95$, moderate; $\mathrm{TE}$ $=6.3 \%$; ICC $=0.31)$. The level of agreement in the direction of asymmetry was 'substantial' $(\kappa=0.62)$.

The mean asymmetry index for the isometric quarter-squat peak force was $8.4 \pm 5.5 \%$ (male $8.3 \pm 5.9 \%$; female $8.6 \pm 5.2 \%$ ). The mean hip extension peak torque strength asymmetry was $6.0 \pm 5.0 \%$ (male 4.6 $\pm 3.9 \%$; female $7.4 \pm 5.6 \%$ ) and $8.1 \pm 5.6 \%$ (male $6.2 \pm 4.8 \%$; female $9.9 \pm 5.9 \%$ ) for hip abduction peak torque. Figure 2 shows the asymmetry scores for each participant, and Table 3 displays the correlations between strength asymmetry and performance, and strength asymmetry and RE. Negligible $(r \leq 0.30)$ or low $(0.31<r \leq 0.50)$ non-significant relationships were observed for strength asymmetry with both performance and RE; however, the exception was female hip abduction strength asymmetry and RE (Figure 3; $r=0.85, p<0.001$ ). Although the correlation between female hip abduction strength asymmetry and performance was low $(r=-0.47)$, it approached the threshold for statistical significance $(p=0.07)$.

Results of independent group testing revealed a significant difference in RE between females classified

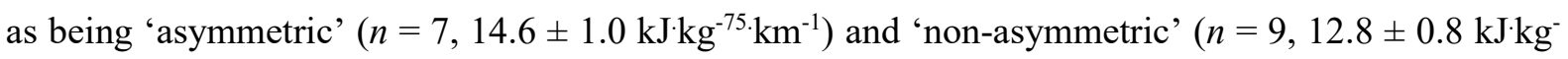
${ }^{75} \mathrm{~km}^{-1}$ ) for hip abduction strength $(\mathrm{t}(14)=-3.85, p=0.002 ; \mathrm{ES}=1.40$, large $)$. There was a 'moderate' difference $(E S=0.72)$ in performance between the same groups; however, this failed to reach statistical significance (Mann-Whitney $\mathrm{U}=16.0, p=0.10$ ). All other between-group comparisons were nonsignificant $(p>0.05)$. Females recorded significantly greater hip abduction peak torque asymmetry compared to males (Mann-Whitney $\mathrm{U}=69.5, p=0.046 ; \mathrm{ES}=0.65$, moderate); however, no betweensex differences were observed for isometric quarter-squat peak force asymmetry (Mann-Whitney $\mathrm{U}=$ 
$106, p=0.58 ; \mathrm{ES}=0.04$, trivial) or hip extension peak torque asymmetry (Mann-Whitney $\mathrm{U}=84.5, p$ $=0.16 ; \mathrm{ES}=0.57$, small . 
Table 2. Test-retest reliability of strength measures $(n=12)$.

\begin{tabular}{|c|c|c|c|c|c|c|c|c|c|c|}
\hline Measure & Side & Trial & Mean \pm SD & ES (descriptor) & TE & TE (\%) & $\mathrm{MDC}_{95}$ & $\operatorname{MDC}_{95}(\%)$ & ICC (95\% CI) & $\begin{array}{c}\kappa \\
\text { (descriptor) }\end{array}$ \\
\hline \multirow{3}{*}{$\begin{array}{l}\text { Bilateral isometric } \\
\text { quarter-squat peak } \\
\text { force }\left(\mathrm{N}^{-0.61}\right)\end{array}$} & \multirow{2}{*}{$\mathrm{R}$} & 1 & $80.9 \pm 14.7$ & \multirow{2}{*}{0.41 (small) } & \multirow{2}{*}{3.6} & \multirow{2}{*}{4.4} & \multirow{2}{*}{10.0} & \multirow{2}{*}{12.2} & \multirow{2}{*}{$0.86(0.61-0.96)$} & \multirow{3}{*}{$\begin{array}{c}0.62 \\
\text { (substantial) }\end{array}$} \\
\hline & & 2 & $83.3 \pm 14.8$ & & & & & & & \\
\hline & $\mathrm{L}$ & $\begin{array}{l}1 \\
2 \\
\end{array}$ & $\begin{array}{l}85.1 \pm 10.7 \\
86.7 \pm 11.3\end{array}$ & 0.95 (moderate) & 5.4 & 6.3 & 15.0 & 17.5 & $0.31(-0.33-0.74)$ & \\
\hline \multirow{3}{*}{$\begin{array}{l}\text { Unilateral isometric hip } \\
\text { extension peak torque } \\
(\mathrm{Nm})\end{array}$} & $\mathrm{R}$ & 1 & $156.8 \pm 46.3$ & 020 (small) & & & & & & \multirow{3}{*}{$\begin{array}{c}0.67 \\
\text { (substantial) }\end{array}$} \\
\hline & K & 2 & $154.1 \pm 43.9$ & 0.20 (small) & 4.4 & 28 & & & & \\
\hline & $\mathrm{L}$ & $\begin{array}{l}1 \\
2\end{array}$ & $\begin{array}{l}156.3 \pm 44.4 \\
157.3 \pm 42.7\end{array}$ & 0.09 (trivial) & 2.2 & 1.4 & 6.1 & 3.9 & $0.99(0.98-1.00)$ & \\
\hline \multirow{2}{*}{$\begin{array}{l}\text { Unilateral isometric hip } \\
\text { abduction peak torque } \\
(\mathrm{Nm})\end{array}$} & $\mathrm{R}$ & $\begin{array}{l}1 \\
2\end{array}$ & $\begin{array}{l}124.5 \pm 30.1 \\
122.2 \pm 35.4\end{array}$ & 0.22 (small) & 3.7 & 3.0 & 10.3 & 8.4 & $0.97(0.89-0.99)$ & \multirow{2}{*}{$\begin{array}{c}0.66 \\
\text { (substantial) }\end{array}$} \\
\hline & $\mathrm{L}$ & $\begin{array}{l}1 \\
2\end{array}$ & $\begin{array}{l}125.4 \pm 32.2 \\
123.3 \pm 36.4\end{array}$ & 0.16 (trivial) & 3.2 & 2.6 & 8.9 & 7.2 & $0.98(0.93-0.99)$ & \\
\hline
\end{tabular}

SD standard deviation; ES effect size; TE typical error; $\mathrm{MDC}_{95}$ minimal detectable change at $95 \%$ confidence interval; ICC intra-class correlation coefficient; $\mathrm{CI}$ confidence interval; $\kappa$ Kappa coefficient; R right leg; L left leg 
Table 3. Results and descriptive interpretation of Spearman rank order correlation tests for strength asymmetry, and performance and running economy.

\begin{tabular}{|c|c|c|c|c|}
\hline & & $\begin{array}{c}\text { Lower limb } \\
\text { extensor bilateral } \\
\text { symmetry index }\end{array}$ & $\begin{array}{l}\text { Hip extension } \\
\text { strength } \\
\text { asymmetry }\end{array}$ & $\begin{array}{l}\text { Hip abduction } \\
\text { strength } \\
\text { asymmetry }\end{array}$ \\
\hline \multirow{3}{*}{ Performance } & Male $(n=15)$ & -0.09 (negligible) & -0.26 (negligible) & 0.05 (negligible) \\
\hline & Female $(n=16)$ & -0.07 (negligible) & -0.20 (negligible) & -0.47 (low) \\
\hline & All $(n=31)$ & -0.06 (negligible) & 0.13 (negligible) & 0.08 (negligible) \\
\hline \multirow{3}{*}{$\begin{array}{l}\text { Running } \\
\text { economy }\end{array}$} & Male $(n=15)$ & 0.30 (negligible) & 0.02 (negligible) & -0.19 (negligible) \\
\hline & Female $(n=16)$ & 0.30 (negligible) & 0.11 (negligible) & $0.85 *$ (high) \\
\hline & All $(n=31)$ & 0.18 (negligible) & 0.01 (negligible) & 0.26 (negligible) \\
\hline
\end{tabular}

$* p<0.001$

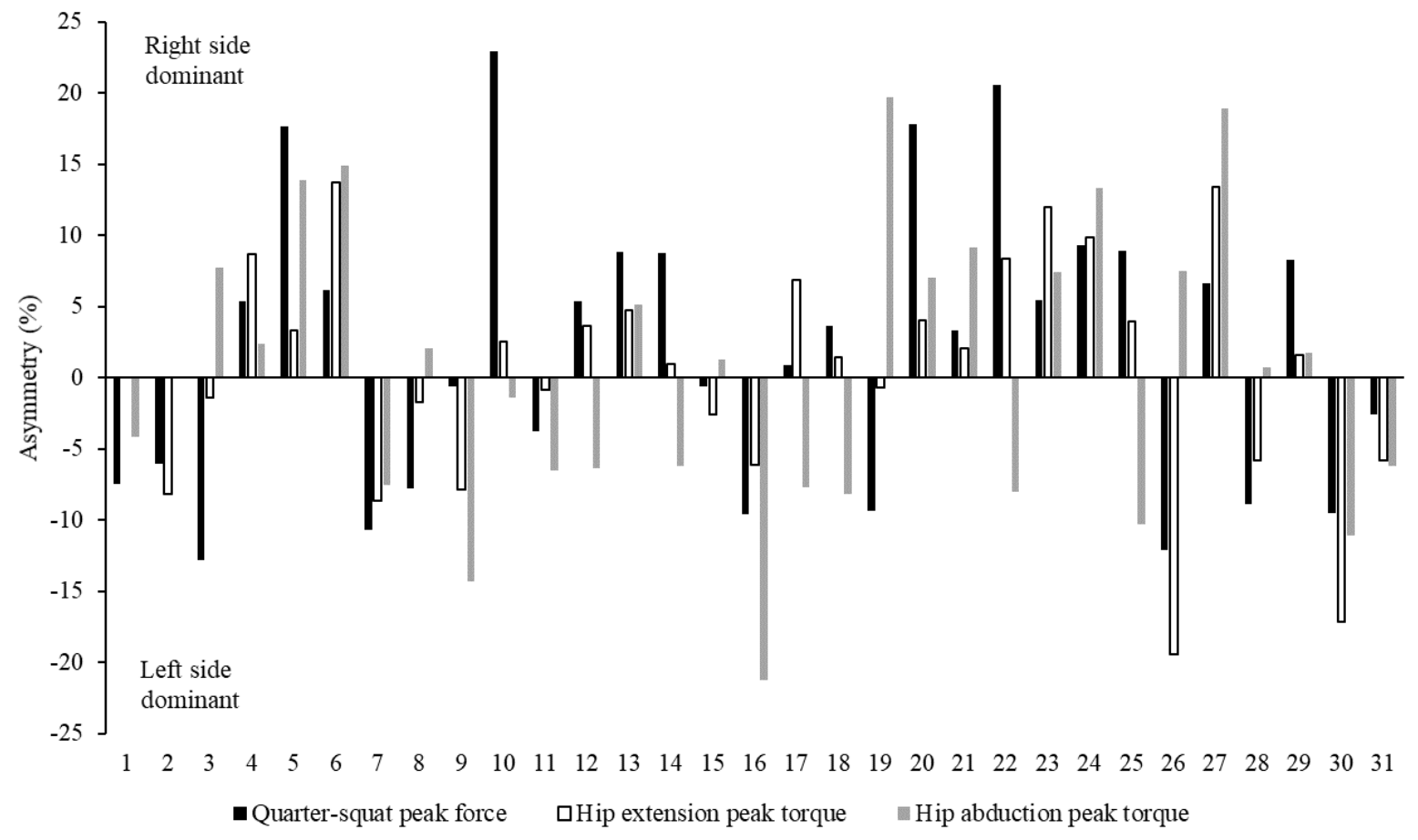

Figure 2. Individual asymmetry scores for isometric quarter-squat peak force, unilateral hip extension peak torque and unilateral hip abduction peak torque (1 - 15 male participants, 16 - 31 female participants) 


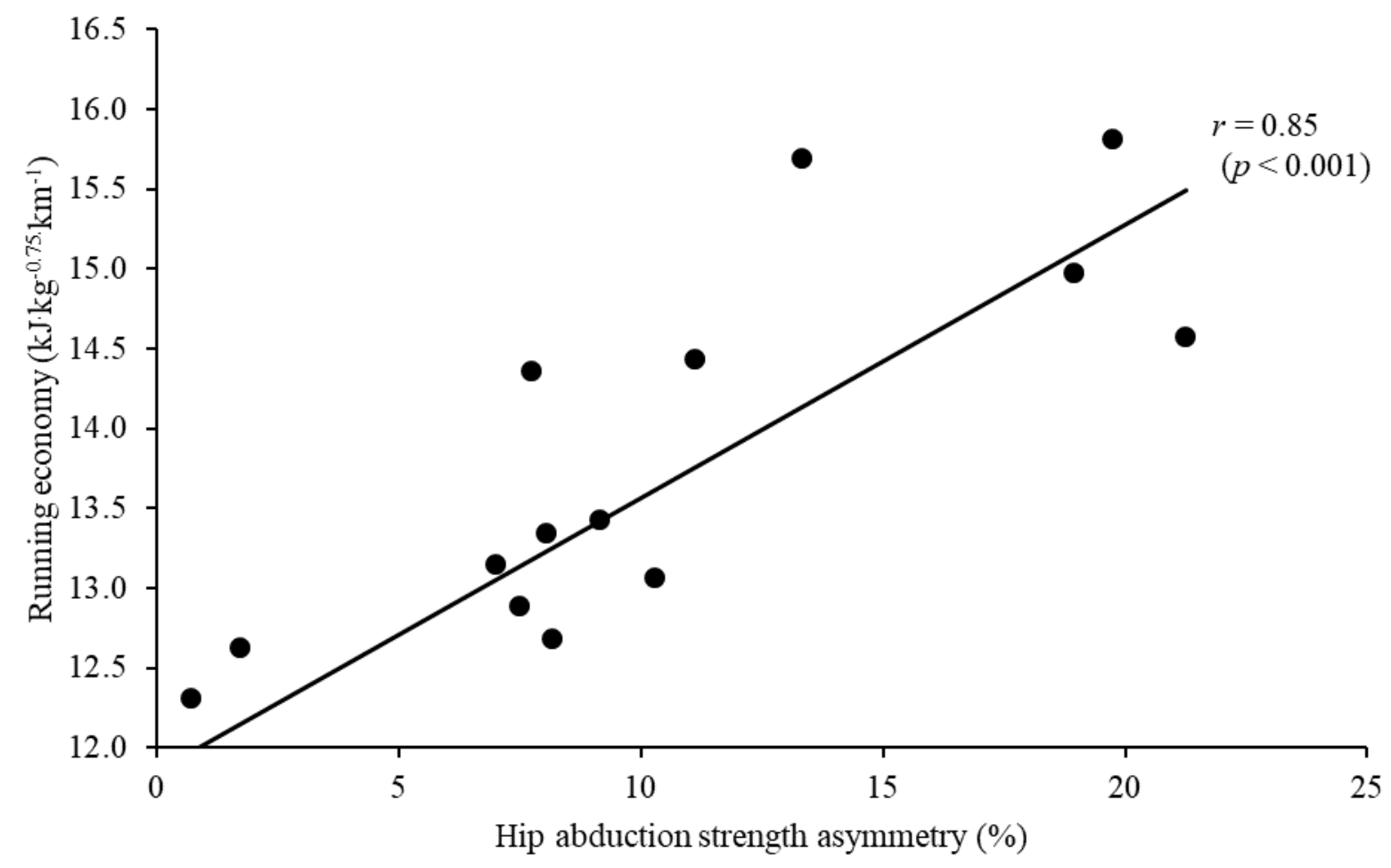

Figure 3. Scatter plot showing relationship between running economy and hip abduction strength asymmetry in female participants $(n=16)$ 


\section{Discussion}

The purpose of this study was to quantify the reliability of isometric strength measures in a group of non-strength-trained adolescent distance runners, and examine the relationships between strength asymmetry, and performance and RE. Test-retest reliability of strength measures was excellent (ES = 0.09 - 0.41; TE: $1.4-4.4 \%$; ICC: $0.86-0.99$ ), with the exception of the left limb during the bilateral isometric quarter-squat test ( $\mathrm{ES}=0.95$; TE: $6.3 \%$; ICC: 0.31 ). The consistency in the direction of asymmetry was also substantial $(\kappa=0.62-0.67)$ for all tests. Correlation analysis revealed negligible or low relationships between strength asymmetry and both performance and RE; however, a strong relationship was noted between hip abduction torque asymmetry and RE for the female participants $(r$ $=0.85, p<0.001)$. In practical terms, as hip abduction strength asymmetry increases in young female runners, RE becomes worse.

Inter-limb asymmetry measured from a single-leg counter-movement jump ${ }^{21,22}$ and iso-inertial concentric power test ${ }^{44}$ has recently been shown to be correlated ( $r=0.46-0.87$ ) with sprinting performance $(5-30 \mathrm{~m})$ in youth team sport athletes. Knee extensor torque asymmetry has also shown a moderate relationship $(r=-0.50)$ with 5 -s power output in endurance road cyclists ${ }^{17}$. These results contrast with those of this study, which showed negligible relationships between inter-limb strength asymmetry and distance running performance and RE. The reasons for the disparity in results is likely due to the magnitude of the asymmetry observed in studies. In the present study, group mean asymmetry values were $\leq 8.1 \%( \pm 5-6 \%)$ for unilateral peak torque tests and were often lower when participants were split into separate male and female cohorts. However, the previous works that have shown associations between asymmetry measured in unilateral tests and sprint performance have recorded larger mean values of $9.0-12.5 \%{ }^{17,21,22,44}$. Although notable inter-limb asymmetries are common in post-pubertal adolescents ${ }^{23}$, they may be exacerbated by the frequent use of a dominant limb in court and invasion game sports. Compared to team sport athletes, the cyclical and largely uniplanar nature of distance running is less likely to cause large inter-limb strength differences.

Previous research has highlighted the importance of displaying individual participant inter-limb asymmetry data due to the large intra-individual variation that can potentially exist between side dominance and tests ${ }^{45}$. Although within-test consistency in the direction of asymmetry was substantial $(\kappa \geq 0.62$, Table 2), individual data (Figure 2 ) appears to confirm that asymmetry is indeed task-specific. In addition, Figure 2 also demonstrates that individual asymmetry values were often vastly different from the mean value, further emphasising the need for an individualised approach to asymmetry analysis. The within-group coefficient of variation (CV) for hip extension peak torque asymmetry was $83 \%$, compared to the lower spread of data in the female hip abduction peak torque asymmetry data $(59.6 \%)$ and previous studies $(55-65 \%)^{8,17,22,44}$. This indicates that very large inter-individual variability in asymmetry data within a cohort may partly explain the weak relationship with performance-related measures. 
The only significant relationship between strength asymmetry and running-related performance factors observed in the present study was for hip abduction peak torque asymmetry and RE in females (Figure $3 ; r=0.85, p<0.001)$, which had the highest mean asymmetry value $(9.9 \pm 5.9 \%)$. Female hip abduction strength asymmetry also displayed a relationship with middle-distance performance that approached statistical significance $(r=-0.47, p=0.07)$. In addition, sub-group analysis, using the $\mathrm{MDC}_{95}$ asymmetry threshold (8.4\%) to split the group, revealed significant $(\mathrm{t}(14)=-3.85, p=0.002)$ and large differences $(\mathrm{ES}=1.40)$ in RE between females categorised as being 'asymmetric' or 'non-asymmetric' for hip abduction peak torque. When the results from this study are combined with findings from previous research ${ }^{17,22,44}$, it appears that inter-limb asymmetry values generated from strength-related field tests of $>9 \%$ are negatively associated with measures relating to running performance in adolescent athletes.

It is likely that over prolonged durations ( $\geq 110 \mathrm{~s}$ ), low-moderate levels of strength asymmetry (< $\mathrm{MDC}_{95}$ ) are compensated for within the locomotor system, thus mitigating the hypothesised change in performance and energy cost of running ${ }^{11}$. However, the female participants who possessed high levels of hip abduction strength asymmetry $\left(>\mathrm{MDC}_{95}\right)$ are likely to have expended more energy during running because their muscles were required to perform more mechanical work during each step ${ }^{10}$. The hip abductor muscles are responsible for proximal control of the hip and frontal-plane control of the knee during the ground contact phase of gait. Consequently, pronounced weakness in one limb is likely to cause larger joint angular displacement ${ }^{46}$, an increase in activation of the weaker muscles and compensatory activation of other muscles ${ }^{47}$. As energy expended by active skeletal muscle represents the majority of the metabolic cost associated with sub-maximal running ${ }^{48}$, it is therefore hypothesised that an increase in net positive muscle mechanical work occurs as hip abduction strength asymmetry increases.

It has previously been noted that females possess greater asymmetry than males for peak force during bilateral jumping, but not on a maximal strength task ${ }^{16}$. Large asymmetry values (12.5 - 16.0\%) have also been reported for female soccer players during unilateral jumps ${ }^{21}$ and female softball players for isokinetic $\left(60^{\circ} \cdot \mathrm{s}^{-1}\right.$ and $\left.240^{\circ} \cdot \mathrm{s}^{-1}\right)$ knee extension and flexion peak torque ${ }^{49}$. In the present study, moderate differences between the sexes were observed for asymmetry in hip abduction peak torque, but not for the other strength tests. The reasons for the apparent difference in asymmetry between the sexes on specific tests are unknown; however, there has been speculation that differences in strength could be partly responsible ${ }^{16}$. Indeed, in the present study, males were on average $\sim 36 \%$ stronger than females in the hip abduction strength test. In addition to the relationship observed between hip abduction peak torque asymmetry and RE, hip abductor weakness is also associated with chronic patellofemoral pain and iliotibial tract friction syndrome in female distance runners ${ }^{50}$. Strengthening of this movement pattern should therefore form an important part of the non-running conditioning routine for female runners. 
High levels of reliability (ICC: 0.96 ; TE: $4.6 \%$ ) have previously been observed for peak force in an isometric mid-thigh pull in youth soccer players ${ }^{27}$. Similarly, unilateral isometric mid-thigh pull ${ }^{28}$ and unilateral isometric quarter-squat ${ }^{29,51}$ peak force has shown excellent reproducibility (ICC: $\geq 0.94$; TE: $\leq 7 \%)$. The ICC value for peak force in the present study (right: 0.86 (95\% CI 0.61-0.96); left: 0.31 (95\% CI $-0.33-0.74)$ ) are lower than those identified for the aforementioned studies; however, the TE appears to be similar (4.4 - 6.3\%), indicating a comparable level of systematic bias exists compared to previous investigations. A wide range of scores is necessary to generate a high ICC statistic; therefore, the differences between studies may be partly attributable to the range of values included in the samples. The between-participant CV for previous studies ${ }^{27,29}$ was $16-27 \%$ compared to $\sim 12 \%$ for the left limb in this study and $>24 \%$ on other tests, suggesting that this may be a factor in the lower ICC recorded. Participants in the present study were also adolescent non-strength-trained athletes, compared to collegiate or professional senior athletes in previous studies ${ }^{28,51}$. Therefore, it is likely that less familiarity with maximal strength tasks in the participants of the present study also contributed towards the differences observed.

The reproducibility of unilateral peak torque during isometric hip extension and abduction tasks was excellent (ICC: 0.97 - 0.99). These reliability values are similar (TE: $4.8-8.1 \%$; ICC: $0.94-0.95$ ) to those reported in a study using a very similar testing position with a dynamometer set-up in ${ }^{32}$ (Nadler et al., 2000). Other investigations that tend to observe poorer reliability use hand-held dynamometry or more than one tester, or attempt to measure peak torque in a standing position ${ }^{30,33,52}$.

This study is not devoid of limitations. Although strength asymmetry provides insight into the importance of the neuromuscular system for RE, biomechanical measures taken during running might have revealed how hip abduction strength asymmetries manifest as differences in between-limb kinematics for the female participants. Secondly, previous research has shown that unilateral jump tests offer a valid and reliable way to quantify inter-limb asymmetry in youth athletes ${ }^{21,44}$; therefore, the addition of dynamic strength-related measures would have been a valuable inclusion to the testing battery. Third, although a high correlation $(r=0.85)$ was observed between RE and hip abduction peak torque asymmetry in females, this does not necessarily imply causality. Future research should therefore investigate whether a strength-training intervention, designed to reduce inter-limb asymmetry, also improves RE. Finally, the sub-group comparison between asymmetric and non-asymmetric participants in the isometric quarter-squat test was underpowered, as only four individuals exceeded the $\mathrm{MDC}_{95}$ threshold, thus increasing the margin of error in statistical testing.

The findings of this study show that unilateral force-producing capabilities possess an acceptable level of reliability in non-strength-trained adolescent distance runners. This study was the first to investigate the relationships between inter-limb strength asymmetry, and performance and RE in this population. Although the mean asymmetry values reported were larger than the intra-limb error in measurement, 
they were lower compared to those reported in other adolescent athletes. Inter-limb strength asymmetry quantified using an isometric quarter-squat and unilateral hip extension test appears to be largely unrelated to performance and RE, whereas hip abduction strength asymmetry displayed an association with RE in the female participants only. Results suggest that inter-limb hip abduction strength differences of $>9 \%$ in females are likely to negatively impact RE and may also adversely affect running performance. Practitioners should consider inter-limb hip abduction strength asymmetry on an individual level and attempt to reduce asymmetry in females to improve RE.

\section{Funder information:}

No funding was received for this study.

\section{Declaration of interest:}

The authors report no conflict of interest. 


\section{References}

1 Bassett Jr. DR, Howley ET. Limiting factors for maximum oxygen uptake and determinants of endurance performance. Med Sci Sport Exerc 2000; 32(1):70-84.

2 Blagrove RC, Howatson G, Pedlar CR, et al. Quantification of aerobic determinants of performance in post-pubertal adolescent middle-distance runners. Eur J Appl Physiol 2019; 119(8):1865-1874. Doi: 10.1007/s00421-019-04175-w.

3 Hoogkamer W, Kipp S, Spiering BA, et al. Altered Running Economy Directly Translates to Altered Distance-Running Performance. Med Sci Sport Exerc 2016; 48(11):2175-2180. Doi: 10.1249/MSS.0000000000001012.

4 Saunders PU, Pyne DB, Telford RD, et al. Factors affecting running economy in trained distance runners. Sport Med 2004; 34(7):465-485.

5 Li F, Newton RU, Shi Y, et al. Correlation of Eccentric Strength, Reactive Strength, and Leg Stiffness With Running Economy in Well-Trained Distance Runners. J Strength Cond Res 2019. Doi: 10.1519/JSC.0000000000003446.

6 Blagrove RC, Howatson G, Hayes PR. Effects of strength training on the physiological determinants of middle- and long-distance running performance: a systematic review. Sport Med 2018; 48(5). Doi: 10.1007/s40279-017-0835-7.

7 Bishop C, Read P, Chavda S, et al. Asymmetries of the Lower Limb: The Calculation Conundrum in Strength Training and Conditioning. Strength Cond $J$ 2016; 38(6).

8 Meyers RW, Oliver JL, Hughes MG, et al. Asymmetry During Maximal Sprint Performance in 11- to 16-Year-Old Boys. Pediatr Exerc Sci 2017; 29(1):94-102. Doi: 10.1123/pes.2016-0018.

9 Cavanagh PR, Pollock ML, Landa J. A biomechanical comparison of elite and good distance runners. Ann N Y Acad Sci 1977; 301:328-345.

10 Beck ON, Azua EN, Grabowski AM. Step time asymmetry increases metabolic energy expenditure during running. Eur J Appl Physiol 2018; 118(10):2147-2154. Doi: 10.1007/s00421-018-3939-3.

11 Seminati E, Nardello F, Zamparo P, et al. Anatomically asymmetrical runners move more asymmetrically at the same metabolic cost. PLoS One 2013; 8(9):e74134-e74134. Doi: 10.1371/journal.pone.0074134.

12 Marconi V, Carraro E, Trevisi E, et al. The Locomotory Index in diplegic and hemiplegic 
children: the effects of age and speed on the energy cost of walking. Eur J Phys Rehabil Med 2012; 48(3):403-412.

13 Beck ON, Taboga P, Grabowski AM. Prosthetic model, but not stiffness or height, affects the metabolic cost of running for athletes with unilateral transtibial amputations. $J$ Appl Physiol 2017; 123(1):38-48. Doi: 10.1152/japplphysiol.00896.2016.

14 Iliopoulos E, Galanis N, Iosifidis M, et al. Anterior cruciate ligament deficiency reduces walking economy in "copers" and "non-copers". Knee Surg Sports Traumatol Arthrosc 2017; 25(5):1403-1411. Doi: 10.1007/s00167-015-3709-2.

15 Hart NH, Nimphius S, Spiteri T, et al. Leg strength and lean mass symmetry influences kicking performance in Australian football. J Sports Sci Med 2014; 13(1):157-165.

16 Bailey CA, Sato K, Burnett A, et al. Force-Production Asymmetry in Male and Female Athletes of Differing Strength Levels. Int J Sports Physiol Perform 2015; 10(4):504-508. Doi: 10.1123/ijspp.2014-0379.

17 Rannama I, Port K, Bazanov B, et al. Sprint cycling performance and asymmetry. J Hum Sport Exerc 2015; 10(1):247-258. Doi: 10.14198/JHSE.2015.10.PROC1.12.

18 Bell DR, Sanfilippo JL, Binkley N, et al. Lean mass asymmetry influences force and power asymmetry during jumping in collegiate athletes. J Strength Cond Res 2014; 28(4):884-891. Doi: $10.1519 /$ JSC.0000000000000367.

19 Hewett TE, Myer GD, Ford KR. Decrease in Neuromuscular Control About the Knee with Maturation in Female Athletes. J Bone Jt Surg Am Vol 2004; 86(8):1601-1608. Doi: 10.2106/00004623-200408000-00001.

20 Beunen G, Malina RM. Growth and physical performance relative to the timing of the adolescent spurt. Exerc Sport Sci Rev 1988; 16(1):503-540.

21 Bishop C, Read P, McCubbine J, et al. Vertical and Horizontal Asymmetries are Related to Slower Sprinting and Jump Performance in Elite Youth Female Soccer Players. J Strength Cond Res 2018. Doi: 10.1519/JSC.0000000000002544.

22 Bishop C, Brashill C, Abbott W, et al. Jumping Asymmetries Are Associated With Speed, Change of Direction Speed, and Jump Performance in Elite Academy Soccer Players. $J$ Strength Cond Res 2019. Doi: 10.1519/JSC.0000000000003058.

23 Rumpf MC, Cronin JB, Mohamad IN, et al. Kinetic asymmetries during running in male youth. Phys Ther Sport 2014; 15(1):53-57. Doi: 10.1016/J.PTSP.2013.03.001.

24 Bishop C, Read P, Chavda S, et al. Using Unilateral Strength, Power and Reactive Strength 
Tests to Detect the Magnitude and Direction of Asymmetry: A Test-Retest Design 2019. Doi: 10.3390/SPORTS7030058.

25 Bazyler CD, Bailey CA, Chiang C-Y, et al. The effects of strength training on isometric force production symmetry in recreationally trained males 2014:6-10. Doi:

10.17338/TRAINOLOGY.3.1_6.

26 Blazevich AJ, Gill N, Newton RU. Reliability and validity of two isometric squat tests. $J$ Strength Cond Res 2002; 16(2):298-304.

27 Dos'Santos T, Thomas C, Comfort P, et al. Between-session reliability of isometric mid-thigh pull kinetics and maximal power clean performance in male youth soccer players. $J$ Strength Cond Res 2017.

28 Dos'Santos T, Thomas C, Jones PA, et al. Assessing muscle strength asymmetry via a unilateral stance isometric mid-thigh pull. Int J Sports Physiol Perform 2017; 12(4):505-511. Doi: 10.1123/IJSPP.2016-0179.

29 Bishop C, Read P, Lake J, et al. Unilateral Isometric Squat: Test Reliability, Interlimb Asymmetries, and Relationships With Limb Dominance. J Strength Cond Res 2019. Doi: 10.1519/JSC.0000000000003079.

30 Cuthbert SC, Goodheart GJ. On the reliability and validity of manual muscle testing: a literature review. Chiropr Man Therap 2007; 15(1):4. Doi: 10.1186/1746-1340-15-4.

31 Mentiplay BF, Perraton LG, Bower KJ, et al. Assessment of lower limb muscle strength and power using hand-held and fixed dynamometry: a reliability and validity Study. PLoS One 2015; 10(10). Doi: 10.1371/JOURNAL.PONE.0140822.

32 Nadler SF, DePrince ML, Hauesien N, et al. Portable Dynamometer Anchoring Station for Measuring Strength of the Hip Extensors and Abductors. Arch Phys Med Rehabil 2000; 81(8):1072-1076. Doi: 10.1053/APMR.2000.7165.

33 Kollock RO, Onate JA, Lunen B Van. The Reliability of Portable Fixed Dynamometry During Hip and Knee Strength Assessments. J Athl Train 2010; 45(4):349-356. Doi: 10.4085/10626050-45.4.349.

34 Exell TA, Irwin G, Gittoes MJR, et al. Implications of intra-limb variability on asymmetry analyses. J Sports Sci 2012; 30(4):403-409. Doi: 10.1080/02640414.2011.647047.

35 Francis $\mathrm{P}$, Ledingham J, Clarke S, et al. A comparison of stride length and lower extremity kinematics during barefoot and shod running in well trained distance runners. J Sport Sci Med 2016; 15(3):417-423. 
36 Jones AM, Poole DC. Physiological demands of endurance exercise. In: Maughan R J, editor. Olympic Textb. Sci. Sport. Int. Olympic Comm. Chichester, UK, Blackwell Publishing, 2009. p. 43-55.

37 Moore SA, Mckay HA, Macdonald H, et al. Enhancing a somatic maturity prediction model. Med Sci Sports Exerc 2015; 47(8):1755-1764. Doi: 10.1249/MSS.0000000000000588.

38 Bishop C, Read P, Lake J, et al. Inter-limb asymmetries: Understanding how to calculate differences from bilateral and unilateral tests. Strength Cond J 2018. Doi:

10.1519/SSC.0000000000000371.

39 Peronnet F, Massicotte D. Table of nonprotein respiratory quotient: an update. Can J Sport Sci 1991; 16(1):23-29.

40 Blagrove RC, Howatson G, Hayes PR. Test-retest reliability of physiological parameters in elite junior distance runners following allometric scaling. Eur J Sport Sci 2017; 17(10). Doi: 10.1080/17461391.2017.1364301.

41 Lolli L, Batterham AM, Weston KL, et al. Size exponents for scaling maximal oxygen uptake in over 6500 humans: A systematic review and meta-analysis. Sport Med 2017; 47(7):14051419.

42 Curran-Everett D. Explorations in statistics: the analysis of ratios and normalized data. $A d v$ Physiol Educ 2013; 37(3):213-219. Doi: 10.1152/advan.00053.2013.

43 Blagrove RC, Howe LP, Cushion EJ, et al. Effects of strength training on postpubertal adolescent distance runners. Med Sci Sports Exerc 2018; 50(6):1224-1232. Doi: 10.1249/MSS.0000000000001543.

44 Madruga-Parera M, Bishop C, Beato M, et al. Relationship Between Interlimb Asymmetries and Speed and Change of Direction Speed in Youth Handball Players. J Strength Cond Res 2019. Doi: 10.1519/JSC.0000000000003328.

45 Bishop C, Lake J, Loturco I, et al. Interlimb asymmetries: the need for an individual approach to data analysis. $J$ Strength Cond Res 2018. Doi: 10.1519/JSC.0000000000002729.

46 Souza RB, Powers CM. Differences in hip kinematics, muscle strength, and muscle activation between subjects with and without patellofemoral pain. J Orthop Sports Phys Ther 2009; 39(1):12-19. Doi: 10.2519/JOSPT.2009.2885.

47 Krogt MM van der, Delp SL, Schwartz MH. How robust is human gait to muscle weakness. Gait Posture 2012; 36(1):113-119. Doi: 10.1016/J.GAITPOST.2012.01.017.

48 Fletcher JR, MacIntosh BR. Running Economy from a Muscle Energetics Perspective. Front 
Physiol 2017; 8:433. Doi: 10.3389/fphys.2017.00433.

49 Newton RU, Gerber A, Nimphius S, et al. Determination of Functional Strength Imbalance of the Lower Extremities. J Strength Cond Res 2006; 20(4):971-977. Doi: 10.1519/R5050501X.1.

50 Mucha MD, Caldwell W, Schlueter EL, et al. Hip abductor strength and lower extremity running related injury in distance runners: A systematic review. J Sci Med Sport 2017; 20(4):349-355.

51 Spiteri T, Cochrane JL, Hart NH, et al. Effect of strength on plant foot kinetics and kinematics during a change of direction task. Eur J Sport Sci 2013; 13(6):646-652. Doi:

10.1080/17461391.2013.774053.

52 Toonstra J, Mattacola CG. Test-Retest Reliability and Validity of Isometric Knee-Flexion and -Extension Measurement Using 3 Methods of Assessing Muscle Strength. J Sport Rehabil 2013; 22(1). Doi: 10.1123/JSR.2013.TR7. 